\title{
Basic science for the clinical gastroenterologist: A review of the recent literature on the small bowel (part 1)
}

\author{
F. Urrutia, MD, R. Fedorak, MD, FrCPC, S. Churnratanakul, MD, M. KeElan, MSC, \\ A.B.R. THOMSON, MD, PHD, FRCPC, FACP
}

E OR SMALL BOWEL BASIC SCIENCE, AS in all parts of medicine, there has been an explosion of information. This is the first of a two-part series in which the scientific basis upon which clinical gastroenterology practice is based is considered and toward which clinical practice is moving.

\section{MORPHOLOGY AND MEMBRANES}

Most mammalian cells have an externally exposed layer of carbohydrates associated with integral membrane glycoprotein and glycolipid. These glycoconjugates have been shown to be receptors for certain bacterial toxins, viruses and a variety of hormones; the importance of receptors in the gastrointestinal tract has recently been reviewed (1). The enterocytes of the luminal brush border membrane and contraluminal basolateral membrane each have different biochemical and functional properties as well as different protein and glycoprotein compositions. The glycoproteins from brush border membranes of proximal and distal intestine are qualitatively different; for example, glycoproteins from distal intestine may have more complete oligosaccharide side chains (2). It remains unknown whether these differences in carbohydrate structure play any role in physiological functions or the initiation or perpetuation of disease.

\section{Can J Gastroenterol 1988;2(2):79-88}

Key Words: Clinical science, Physiology, Recent advances, Small intestine

Nutrition and Metabolism Group, Division of Gastroenterology, Department of Medicine, University of Alberta, Edmonton, Alberta

Correspondence and reprints: Dr A.B.R. Thomson, Nutrition and Metabolism Group, Division of Gastroenterology, Department of Medicine, 519 Robert Newton Research Building, University of Alberta, Edmonton, Alberta T6G 2C2. Telephone (403) 432-6490

Received for publication March 29, 1988. Accepted April 27, 1988

Phosphatidylcholine (PC) is a major phospholipid of brush border membrane and may be synthesized from: acylation of lysophosphatidylcholine; de novo synthesis via the reaction of diacylglycerol with CDP choline; or enzymatic conversion of phosphatidylethanolamine (PE) to $\mathrm{PC}$ by methylation reactions utilizing $\mathrm{S}$-adenosyl-L-methionine as the methyl donor (the so-called PEMT pathway). The latter reaction is present in rat small intestinal brush border membranes (3). While the specific activity of this membrane enzymatic reaction is low compared to that of other plasma membranes, such transmethylation reactions may influence transepithelial sodium transport and may represent the mechanism by which the degree of fatty acyl saturation in membrane phospholipids may be altered, thereby influencing brush border membrane function.

Lipid-lipid and lipid-protein interactions in biological membranes play a major role in their functions. Lipid peroxidation of biological membranes has been attributed to exert a primary effect in the process of a variety of pathological events, including radiation inju- 
ry, ischemic damage and ageing. Biological membranes are readily susceptible to peroxidative attack, because they are rich in unsaturated fatty acids. Lipid peroxidation reduces the lipid fluidity of intestinal brush border membranes (4), with associated alterations in the activities of membrane bound enzyme and transport processes.

Changes in membrane fatty acid saturation induced by dietary manipulation also result in alterations in the activity of intestinal $\mathrm{HMG}-\mathrm{Co} A$ reductase and acyl cholesterol acyl transferase (ACAT) activity (5), enzymes important in cholesterol metabolism. Feeding n-3 fatty acid-containing fish oil to rabbits increases hepatic HMG-CoA reductase and ACAT activity, an effect similar to that observed in animals ingesting cholesterol. In the intestine, ACAT activity is not affected by the ingestion of fish oil, whereas $\mathrm{HMG}-\mathrm{CoA}$ reductase activity is decreased in the ileum. The alterations in the activity of these two microsomal enzymes involved in cholesterol metabolism may be due to enrichment of $n-3$ polyunsaturated fatty acid in the hepatic and intestinal microsomal membranes. Fish oils may have a beneficial lipid lowering effect, possibly due to the alteration in hepatic and intestinal cholesterol metabolism.

Dietary protein is hydrolyzed in the intestine by the combined action of pancreatic proteases and the peptidases of the intestinal enterocyte. Peptidases have been identified in the brush border membranes of mammalian small intestinal cells. Several of these intestinal peptidases have been purified, including aminopeptidase $\mathrm{N}$, aminopeptidase $\mathrm{A}$, dipeptidyl aminopeptidase IV, gammaglutamyltranspeptidase, folate conjugase, a carboxypeptidase and peptidyl dipeptidase. Neutral endopeptidases are also integral components of the brush border membrane and function in concert with aminopeptidase $\mathrm{N}$ to hydrolyze dietary protein (6).

Alkaline phosphatases are present on the membranes of almost all human cells. Partial sequencing of human adult, human fetal and bovine intestinal alkaline phosphatases has been described (7). The anchoring and biosynthesis of stalked brush border membrane protein have been reviewed (8). Sucrase-isomaltase, an integral carbohydrase of the small intestinal brush border membrane, is responsible for the surface hydrolysis of both sucrose and the products of intraluminal starch digestion which must occur prior to monosaccharide absorption. Sucrase-isomaltase appears to be synthesized as a single chain peptide, is glycosylated and transported to the brush border membrane. Here it is cleaved into subunit form, with the sucrase and isomaltase subunits thereafter linked by noncovalent forces. Using immune electron microscopy, the sucrase-isomaltase proteins have been found in the brush border membrane, endoplasmic reticulum, nuclear envelope, Golgi complex, smooth apical vesicles and in the multivesicular bodies (9). These findings are consistent with the concept of synthesis, translocation and initial glycosylation of plasma membrane proteins occurring at the membrane of endoplasmic reticulum, and then further processing occurring in the Golgi complex. The final step of intracellular movement, transfer to the brush border membrane, may be mediated by apical membrane vesicles.

Amino-oligopeptidase (AOP), an integral digestive enzyme of the brush border, hydrolyzes the oligopeptides produced by luminal pancreatic proteases at the intestinal membrane surface in preparation for intestinal transport of the final dipeptide and amino acid product. Intraintestinal infusion of a tetrapeptide substrate or a synthetic substrate induces doubling of the incorporation of ${ }^{3} \mathrm{H}$-leucine into the AOP (10). The rapid synthesis of AOP as a nascent protein occurs with the endoplasmic reticulum within 15 mins after an intestinal amino acid 'pulse-chase' in association. Thirty minutes later, apparent post translational glycosylation and transfer to Golgi membrane takes place. Because only a short hydrophobic segment of the amino peptidase is embedded within the brush border membrane (whereas most of its domains are exterior to the cell surface), transduction of a signal to the intracellular synthetic machinery may require a second messenger. The abrupt enhancement of digestive enzyme synthesis by its luminal substrate constitutes a precise local mechanism for regulation of intestinal nutrient digestion. There are probably other examples still to be discovered of locally regulated enzyme content in the intestine.

The small intestinal epithelium represents a system of continuous cell renewal; mitotically active cells, present in the region of the crypts, give rise to differentiated nonproliferative cells which migrate along the length of the villi and are eventually lost into the intestinal lumen. When the newly differentiated cells reach the top of the crypts or the base of the villi, they acquire distinctive ultrastructural features and surface membrane enzymes. Cell proliferation in the crypts is a steady-state process, with a constant frequency distribution of cells throughout the mitotic cycle. This proliferation is precisely balanced by cell loss at the tips of the villi. The crypts are populated by a heterogeneous cell population and are assumed to represent a pool of stem cells. Using monoclonal antibodies prepared against luminal membranes, specific surface membrane components of the intestinal crypt cells have been identified (11). This suggests that fetal antigens may be retained in the cells after birth. Maintenance of the differentiated state of the epithelial cells may require mesenchymal and/or extracellular matrix components (12).

Initiation of systemic viral disease requires that viruses first penetrate the brush border membrane. These viruses may replicate and produce disease locally and/or disseminate to distant organs via the lymphatics or blood supply. Adherence of reovirus to the apical surface of mucosal epithelial cells is nonselective in newborn mice. Adherence becomes more selective within the first post natal week, with adherence by day 7 to most membranous epithelial cells (M cells), to a variable number of undifferentiated cells, but to few absorptive cells (13).

Peyer's patches are known to be a functional part of the gut-associated lymphoid tissue. The epithelium covering the dome of the lymphoid follicles within Peyer's patches plays a specialized role in the uptake and processing of antigen from the lumen of the gut. The epithelium transports antigen from the lumen to underlying lymphocytes and macro- 
phages. The protruding dome-like surface of the follicle, the presence of $\mathrm{M}$ cells of epithelial origin, intraepithelial lymphocytes and the relative absence of mucous secreting goblet cells within the follicle epithelium all appear to assist in the trapping and transport of antigen. The unique structure of the basement membrane overlying lymphoid follicles suggests a biological adaptation of this tissue boundary to a specific physiologic activity of the organism (14).

\section{UNSTIRRED WATER LAYERS}

The unstirred layer adjacent to the mucosal surface of the intestinal epithelium complicates the interpretation of absorption data, with underestimation of the intestinal permeability properties, overestimation of the apparent Michaelis constants of carrier-mediated transport and shifting of the $\mathrm{pH}$ absorption curve to either the right or the left. In the closed rat jejunum, intraluminal diffusion is the rate limiting step in the absorption process of highly permeant substances (15). Increasing the viscosity of the perfusion solution by the addition of methylcellulose increases the pressure in the intestinal lumen, distends the intestinal wall and increases antipyrine absorption (16). The reduction of absorption of drugs such as antipyrine, benzoic acid and $\propto$-methyl-D-glucoside corresponded approximately with the reduction of the diffusion coefficient. Guar gum reduces the intestinal absorption of nutrients, probably by increasing the thickness of the intestinal unstirred water layer (17).

\section{SMALL BOWEL RESECTION AND ADAPTATION}

The topic of adaptation of intestinal nutrient transport has been reviewed (18). The adaptive response following intestinal resection includes changes in intestinal structure, epithelial cell production, cell migration of enterocytes up the villus, the activities of brush border and intracellular enzymes, as well as absorptive function. Recent work on adaptation has been organized around four central issues: the pattern of adaptation; its mechanistic basis; the time course and reversibility of adaptation; and the signal for adaptation.
The physiological significance of the rate of absorption rather than its completeness has been considered. Numerous transporters are regulated by dietary substrate levels (19). Regulatory patterns vary greatly among transporters; two sugars and two nonessential amino acids upregulate their own transporters, two vitamins and three minerals downregulate their own transporters, and two transporters of essential amino acids respond nonmonotonically to levels of their substrates. These varied patterns arise from trade-offs among four factors: transporter costs; calories yielded by metabolizable substrates; fixed daily requirements of essential nutrients; and toxicity of certain nutrients when taken in large amounts. While individual amino acids cause an adaptation of amino acid uptake, the effects are nonspecific and independent of their metabolic or trophic potential (20). The uptake of hexoses and lipids is influenced by variations in fat content of the diet in animals with an intact intestinal tract or following an ileal resection (21).

Three major factors are currently under discussion as being responsible for the maintenance and adaptation of small intestinal growth: nutrients, pancreaticobiliary secretions and hormones. Intestinal vasoactive intestinal peptide (VIP), increases after small bowel resection and this peptide may be a mediator of cell proliferation and differentiation in intestinal mucosa. There is loss of potency of VIP in stimulating cyclic-AMP in resected rats, accompanied by a decrease of the affinity of VIP binding sites, as compared with control animals (22).

Neurotensin may also be important in the intestinal adaptive response; neurotensin is a potent stimulant of pancreatic exocrine secretion, and the ileal mucosa is the storage site for approximately $90 \%$ of total neurotensin. Release of ileal neurotensin occurs after a fatty meal, following calcium infusion or during perfusion of the proximal but not the distal intestine with fat (23). This release of neurotensin is abolished by resection of the distal small bowel, and release of neurotensin in the distal gut appears to be dependent on a signal from the proximal intestine. The nature of this signal from proximal to distal bowel is un- known, and the ultimate physiologic role for neurotensin released from the ileum remains uncertain.

The trophic effect of luminal nutrition may be mediated through the release of these or other regulatory peptides with endocrine or paracrine effects. Enteroglucagon is the strongest candidate for the role of 'enterotrophin' while cholecystokinin markedly influences pancreatic growth. The pancreas has a trophic influence on the small bowel mucosa, and the intestine, in turn, influences the growth, structure and function of the exocrine pancreas.

After partial small bowel resection, compensatory changes occur in the morphology and function of the remaining intestine. For example, there is increased passive uptake of phenylalanine across rat small intestine in ileal resected animals (24). There are also variable changes in the in vitro uptake of glucose, galactose and fructose six weeks after resection of the distal half of the rabbit jejunum (25). The direction and magnitude of the transport changes depend upon the method used to express the rates of uptake, the transport preparation used and the diet fed to the animals (26). For example, the transport of nutrients may be unaltered by resection when studies are undertaken with isolated intestinal epithelial cells or brush border membrane vesicles, yet may be increased using discs of intestine in vitro.

In addition to the decreased absorptive surface area following resection, there may be a larger number of new, small and less mature cells with decreased enzymatic activity and specific transport capacity. The length of the intestine removed, its anatomical location and the duration allowed for adaptation are all important factors which influence the adaptive changes. The presence of elemental diet or enteric enzymes in the lumen, or the release of hormones stimulated by food ingestion all appear to play a significant role in this process of adaptation.

Adaptation of electrolyte transport in the cecum and colon occur after $60 \%$ jejunoilectomy $(27,28)$. The additional excision of the cecum may provoke an alteration in the cell mass and function in the colon, without changes in 
$\mathrm{Na}^{+} \mathrm{K}^{+}-$ATPase activity. Overall, these processes tend to conserve sodium, chloride, water, potassium and probably bicarbonate, thereby contributing to the survival of the animal. In man, adaptive changes occur slowly after ileal bypass for heterozygous familial hypercholesterolemia, resulting in gradual normalization of cholesterol absorption despite continuing bile acid malabsorption (29).

The importance of intraluminal nutrition in the stimulation of mucosal hyperplasia is well known, and certain nutrients such as long-chain fats appear to have a greater stimulatory effect than others. Survival following massive resection of the small intestine is often possible due to substantial hyperplasia of the mucosal surface of the remaining small intestine. $\mathrm{PGE}_{2}$ (16,16-dimethyl-prostaglandin $E_{2}$ ) given intragastrically to rats with massive small bowel resection augments mucosal adaptation in the remaining proximal small intestine (30). The antitrophic effects of indomethacin, a prostaglandin synthesis inhibitor, indicates that endogenous prostaglandins may also participate in the epithelial cell regulation of the gastrointestinal tract (31).

Following massive resection of the mid-small intestine, calcium uptake from in vivo perfused segments is decreased, yet the intestinal adaptation may be sufficient to maintain normal net transport, as measured by balance studies (32). Massive jejunal resection also alters the duration of the migrating myoelectric complex cycle in the remaining jejunum and ileum, although no direct relationship is detectable between intestinal trophic changes and the recoordination of cyclic motor pattern following resection or bypass (33).

A 3T3 fibroblast cell culture system has been used to delineate the presence of growth stimulating luminal factors. Characterization of the plasma fraction with growth factor activity appearing after resection revealed it to have a molecular weight of between 6000 and 14,000 (34). Some evidence suggests that enteroglucagon may be trophic to the small intestine and may be one candidate for this plasma trophic factor activity. Several of the 3T3 cell mitogens also deserve mention, including platelet-derived growth factor, epidermal growth factor, insulin and insulin-like growth factor I, and fibroblast growth factor (35).

Epidermal growth factor (EGF), pentagastrin and glucagon have trophic effects on the gastrointestinal mucosa, but only EGF increases ornithine decarboxylase (ODC) and s-adenosylmethionine activity (36). This suggests that EGF binds to the serosal surface of the crypt enterocyte, and subsequent ODC induction may be important in initiating the cellular proliferation that is known to occur after treatment with this peptide.

Luminal factors cannot explain all the changes occurring in the adaptation process, and experimental evidence indirectly suggests the presence of circulating humoral factors with trophic effects on small intestinal mucosa. Although there is evidence to suggest a mechanism of feedback regulation of cell proliferation by differentiated villous cells, the mechanisms and control of cell renewal in the small intestine are unknown. Several gastrointestinal hormones found to be trophic for the intestine are considered as potential candidates in the response to resection. A heat stable acidic extract of the mucosa of the proximal intestine of rats taken four days after a $50 \%$ small bowel resection was capable of stimulating DNA synthesis of mouse jejunal explants in organ culture (37). This stimulatory activity was not detectable one week after resection when presumably a new steady-state had been established.

This growth stimulating activity of the small intestine did not effect DNA synthesis in other tissues and was due to the presence of two distinct molecules with approximate molecular weights of 4500 and 1500 . These two growth stimulating molecules are present in the proximal but not in the distal intestine in response to resection, are probably peptides and could play a role in promoting the resection associated hyperplasia. A lack of detectable activity in the distal intestine and colon suggests that the mechanisms regulating jejunal mucosal growth may be different from those of the ileum.

The presence of urogastrone-epidermal growth factor (uro-EGF) in a variety of body fluids, including saliva, plasma and milk, its production by the salivary and Brunner's glands, the trophic action of saliva on the intestine, the demonstration of uro-EGF receptors in intestinal epithelial cells and the reported cytoprotective effects on the duodenal mucosa, all suggest that uro-EGF has a role in the control of gastrointestinal homeostasis. Continuous infusion of recombinant B-urogastrone, at a dose below that needed to inhibit gastric acid secretion, largely prevented the decrease in crypt cell production rate and gastrointestinal tissue weight normally observed in parenterally fed rats (38).

The peptide $B$-urogastrone-human EGF has yet to be established as having a physiological role despite its main sites of production in the salivary glands and Brunner's glands of the duodenum of man and rats. Rat and human EGF have similar chemical, physical and physiological properties, and both stimulate ODC as well as the proliferation and maturation of the neonatal intestine. One of the in vivo actions of uro-EGF is the maintenance of gastrointestinal growth and EGF occurs through a systemic rather than a luminal mechanism (39).

The nutritional and metabolic consequences of extensive bowel resection have been reviewed $(40,41)$. Malabsorption of protein, carbohydrate, fat and divalent cations occurs after extensive loss of small bowel. The process of adaptation and compensatory hypertrophy intravenes, and with time there is an improvement in the ability of the bowel to absorb nutrients and a corresponding decrease in diarrhea. Patients with short bowel syndrome who have been stable for at least one year and who can tolerate oral diets do not need to restrict fat intake or to separate fluids from solids during their meals (42). These patients may need to take oral supplementation of calcium, magnesium and zinc to maintain divalent cation balance. Those who increase their oral intake to 35 to $40 \mathrm{kcal} / \mathrm{kg}$ ideal body weight should consume 80 to $100 \mathrm{~g}$ protein per day in order to maintain a positive nitrogen balance.

The adaptive changes that occur after extensive intestinal resection depend on several factors: length and location of remaining intestine; presence or absence of visceral resection (gastric, colonic or 
rectal); and nature of the disease responsible for the decision to resect a relatively large portion of intestine. Patients with short bowel syndrome may be classified as a function of remaining gut length, the duration of required nutrition support and the required nutritional support (43). Carbohydrate malabsorption may be a major cause of the watery diarrhea seen in patients with short bowe syndrome (44), but the importance of a low versus a high fat diet remains controversial (45). Fur ther controversy continues as to the optimal diets for patients with only part of the jejunum remaining after resection of the distal small intestine and colon.

In a group of seven patients with a high jejunostomy, there were no consistent differences (in percentage of calorie, nitrogen or fat absorption) between a chemically defined liquid diet (consisting of small peptides, oligosaccharides and low fat content) compared with a liquid polymeric diet (of whole protein, polysaccharides and long chain triglycerides) or three solid food diets (46). Perhaps a liberal attitude is appropriate toward the fat and fibre content of the diet in such individuals. Patients with a high output jejunostomy may also benefit from cimetidine (47). The massive loss of intestine appears to be a contributing factor to the development of hepatic cholestasis and fibrosis which occurs in some patients maintained on prolonged parenteral nutrition (48).

The role of dietitians in enteral feeding has been acknowledged (49). Care must be taken to ensure that bacterial contamination of the enteral diets does not occur (50). In the initial phases of administering enteral tube feedings, the optimal nutrient delivery is frequently limited by the development of abdominal distress and diarrhea. There is usually no need to initiate alimentation with low flow rates or diluted formula (51).

While total parenteral or enteral nutrition permits long term survival in patients after massive intestinal resection, the important strategies for preserving intestinal length in the short bowel syndrome must not be overlooked (52); the judicious use of appropriate surgical procedures can preserve intestinal length and obviate the need for long term par- enteral nutrition in patients after massive intestinal resection (40).

Ornithine decarboxylase (ODC) is the initial rate limiting enzyme in polyamine biosynthesis, converting ornithine to putrescine. ODC synthesizes the first of a series of compounds collectively known as polyamines, which are known to play a role in the regulation of DNA synthesis. ODC is an important mediator in the return of both normal intestinal function and morphology following refeeding. Induction of ODC would appear to involve a receptor-mediated event which is probably located at the luminal cell surface, rather than depending upon the nutritive value of the luminal contents. An increase in ODC activity is associated with cellular proliferation, with exposure to trophic stimuli (such as hormones and growth factors), and with tissue regeneration.

ODC has a rapid turnover with a halflife of approximately $30 \mathrm{mins}$. In the small intestine there is a high basal activity of ODC and following a meal mucosal ODC is activated, predominantly by direct stimulation by dietary constituents and to a lesser extent by humoral mechanisms (53).

Dietary amines may be one of the agents involved in directly increasing ODC activity. Epidermal growth factor and glucagon are also effective inducers of ileal ODC activity (54). Although ODC activity may be blocked by difluoromethylornithine (DFMO), DFMO has no effect on mucosal growth in fed rats and only partially prevents trophic response to refeeding. This suggests that polyamines which are necessary for growth of gastrointestinal mucosa following feeding are not supplied by the rapid activation of mucosal ODC (55).

Polyamines may be important in the intestinal adaptive process $(56,57)$. Putrescine is synthetized from the amino acid ornithine under the influence of the rate limiting enzyme ODC. The levels of putrescine may also be reduced by degradation to spermidine and permine by the enzyme diamine oxidase (DAO).

$\mathrm{DAO}$ is an enzyme which deaminates histamine and polyamines and has its highest activity in the intestinal mucosa. It is found almost exclusively in the small intestine; plasma levels correlate with mucosal DAO content and structural changes in the intestinal mucosa. Total parenteral nutrition is associated with intestinal hypoplasia and reduced DAO mucosal levels (58). Since serum DAO levels are known to correlate with mucosal DAO content, DAO activity may prove useful as a circulating marker of the effect of nutritional therapy on the intestinal mucosa. Some $90 \%$ or more of the body's store of DAO is found in the tips of the small bowel villi. ODC is present in all mammalian cells but is preferentially associated with small intestinal villus rather than crypt cells. A transient increase in ODC activity is associated with the onset of the adaptive mucosal hyperplasia which often follows intestinal resection, and ODC will stimulate DNA, RNA and protein synthesis with consequent crypt cell production and villus hyperplasia.

The associations of increased ODC and s-adenosylmethionine decarboxylase and resulting polyamine levels with growth are well known. The dramatic mucosal ODC increase after acute refeeding comes entirely from villus cell fractions, not from progenitor cells in the crypts, suggesting that ODC is not directly involved in the initiation of cell proliferation. EGF when given intraperitoneally but not intragastrically, stimulates ODC activity along the crypt-villus column (36). This suggests that EGF binds at the serosal surface of the enterocyte crypts, and subsequent ODC induction may be important in initiating the cellular proliferation that is known to occur after treatment with this peptide (36).

Malassimilation of food induces intestinal growth and increases the content of brush border membrane enzymes in the distal but not in the proximal part of the small intestine (59). Long chain triglycerides are important stimulators of adaptive growth (60). Luminal nutrients such as long chain fatty acids may reach the ileum and stimulate increased enteroglucagon release, triggering an intracellular cascade involving ODC and polyamines, which in turn stimulates RNA polymerase, DNA, RNA and protein synthesis, cell division and adaptive growth (61).

Massive resection of the small intestine is often necessary in the treatment 
of adult patients with vascular insufficiency or extensive Crohn's disease of the small intestine, and in infants with necrotizing enterocolitis or congenital anomalies of the gastrointestinal tract. A combination of intravenous nutrition and ad libitum oral feedings with regular diet may represent the best method of nutritional support in the early post resectional period (62). Even in sucking animals in which the intestine is already growing rapidly, it is possible to demonstrate mucosal hyperplasia enhanced by luminal nutrition (63).

Perfusing glucose into the distal ileum of rats and jejunal in vivo uptake of glucose or galactose, or the administration of cyclohexamide, abolished the increase in active glucose absorption induced by distal maltose perfusion (64). Thus, the composition of the intraluminal contents in the distal ileum can influence hexose absorption at a more proximal site, and this response requires that the sugar be perfused for a minimum of $3 \mathrm{~h}$. It is possible that distal perfusion releases peptides such as enteroglucagon or neurotensin, which in turn might modify proximal absorption. Sugars such as glucose, fructose, sucrose and galactose maintain intestinal mass when infused individually into parenterally fed rats, and a similar trophic response has been reported for infusion of mixtures or individual amino acids.

Adaptation of absorption appears to possess certain specificities: infusion of glucose does not affect leucine active transport and, while various amino acids may be trophic to the intestine, their effects on in vitro uptake are variable and nonspecific (65); for example, prior lysine and aspartic acid infusion increased in vitro uptake of lysine, aspartic acid and valine. Thus, there are interrelationships between the presence of luminal nutrients and regulation of nutrient absorption.

Mucosal growth may be stimulated by the absorption of sugars, and enteral disaccharides stimulate mucosal growth more than equivalent amounts of monosaccharides (66). This is possibly because the 'work of hydrolysis' enhances growth stimulation. Two dietary fibres, guar gum and carboxymethylcellulose, reduce intestinal nutrient absorption, in- crease the rate of production of mucosal cells in the small and large intestine, and reduce the mucosal alkaline phosphatase and lactase levels (67). Thus, the digestive, absorptive and growth aspects of the intestine may be influenced by events occurring in the intestinal lumen.

Jejunal disaccharidase and leucine aminopeptidase (LAP) activity in the brush border play an impor tant role in the digestion and absorption of dietary nutrients. Intestinal maltase is influenced by the quality and quantity of dietary protein, while LAP activity is only changed by the quality of protein (68). Restricting a balanced diet does not significantly affect disaccharidases, in contrast to the known effects of dietary protein restriction (69). Differing responses occur with starvation for the proximal and distal small intestine, and this suggests the presence of distinctly differing mechanisms for the control of the mucosal mass and enzyme activities in these sites (70).

The activity of superoxide dismutase increases following intestinal resection (71). With starvation, there is mucosal hypoplasia and reduction in the rate of cell proliferation together with reduced uptake of glucose. However, refeeding induces a rapid return to the pre-starvation state and, coincidentally, there is a large increase in the activity of the enzyme ODC.

\section{IMMUNOLOGY AND TRANSPLANTATION}

The immunological mechanisms in intestinal diseases have been reviewed (72). With the introduction of cyclosporine, long term survival of small bowel allografts across strong immunogenetic barriers has been achieved, but as yet only in animals. Prolonged allograft survival has created a need for a reliable method of diagnosing and following rejection in intestinal allografts. A sequence of histologic changes in acute and chronic rejection has been described in a rat model of small bowel transplantation $(73,74)$. Re-establishing physiologic portal venous drainage is technically difficult but may be superior to the use of systemic venous drainage in small bowel transplantation (75). Graft-versus-host reactions have been described (76) and im- proved survival after allogeneic small intestinal transplantation may be achieved by using cyclosporine immunosuppression (77).

\section{ABDOMINAL IRRADIATION}

The topic of radiation damage to the small intestine has been reviewed (78). Radiation therapy has been found to be effective primary therapy in such cancers as squamous cell carcinoma of the cervix and adenocarcinoma of the endometrium. During radiation therapy, normal tissues unavoidably sustain varying amounts of damage. Among the most serious complications of radiation therapy encountered by a patient with malignant disease is that of radiation injury to the small intestine. Factors known to influence the severity of injury to normal tissue include the radiation dose, the technique employed and the sensitivity of the tissue to radiation. The development of post irradiation injury is often a barrier to achieving maximal tumouricidal doses and can be a major source of morbidity for patients undergoing radiotherapy.

lonizing radiation has a direct effect on the gut wall that occurs during or shortly after a course of radiotherapy. Collectively, these effects are termed the 'gastrointestinal radiation syndrome' There often follows a progressive obliterative vasculitis that can result in ischemic changes many years after the initial treatment. There is often a long, latent period between the completion of the radiotherapy and the onset of chronic symptoms. Although symptoms may start insidiously, once established the disease follows a relentless course. Lesions include fistulas, perforations and bleeding, which often occur in the rectosigmoid and mid-or distal small bowel.

The small intestine is a major critical organ at risk in the radiation treatment of the abdomen. Late severe injury in the small bowel is usually expressed as obstructive stenosis, mucosal ulceration, perforation and malabsorption. The extent and severity of late radiation injury is determined by the volume of irradiated tissue, total radiation dose and fractionation schedule. The intestinal mucosa, connective tissue and microvasculature are critical target tissues. 
Retrospective studies suggest an incidence of post radiation injury of $5 \%$ to $50 \%$ of patients, depending upon the manner of identifying intestinal involvement. The clinical spectrum of post radiation injury to the small and large bowel includes proctocolitis, strictures, obstruction, chronic blood loss and fistulization (to the vagina, urinary tract or skin). Acute radiation to the small intestine causes reversible destruction of the mucosal epithelium. Whereas the acute intestinal effects of radiation are well recognized and are usually self-limited, the chronic effects may be delayed for over a decade. It should be noted that severe malnutrition due to the intestinal malabsorption which often accompanies post radiation enteritis may be interpreted as tumour recurrence.

When mice are given 14 doses of $3 \mathrm{~Gy}$ over two weeks with a partial abdominal irradiation field, there is late injury in the intestinal epithelium, submucosa and subserosa (79). There is reduced crypt number and villus atrophy three and six months following radiation treatment. The mitotic activity in the crypts of irradiated animals is increased, although insufficiently to maintain mucosal integrity. Intestinal vascular perfusion, is only transiently reduced at three months after radiation. This suggests that there was no major influence on blood flow although there remains the possibility of microischemic zones or redistribution of blood from the mucosa to the submucosa following irradiation.

Tritiated thymidine and other radiolabelled precursors of DNA have been used to study the influence of radiation on cells. Their incorporation into DNA is very sensitive to ionizing radiation. In renewing hierarchical cell populations, where cells undergo a step-by-step differentiation/maturation from stem cells to functional cells, different sensitivities to radiation may exist within such lineages. The efficiency of the incorporation of ${ }^{3} \mathrm{H}$-thymidine into cells of small intestinal crypts is dependent on the position of the proliferative cells in the crypt. These in turn may be a reflection of differences in the activity of thymidine kinase in cells at different stages of differentiation, or differences in the size of the endogenous pools of the precursor or its derivatives. Very low doses of radiation also inhibit thymidine kinase and change the levels of the systemic or regional extracellular pools of precursors for DNA synthesis.

In the small intestine of the mouse, the efficiency of the incorporation of ${ }^{3} \mathrm{H}$-thymidine by the salvage pathway of DNA synthesis by cells at the crypt base (stem cell zone) was twice as high as for the S-phase maturing proliferative cells at the top of the crypt (80). Thus, the relationship between the de novo and salvage pathways of DNA synthesis seems to be dependent on position both in a topographical sense and from the point of view of hierarchical status within the cell lineage. Fractionated irradiation generally results in less tissue damage than the same total radiation dose given as a single exposure. This is considered to be due mainly to intracellular recovery from sublethal damage which is complete within a few hours after irradiation. The degree of radiation injury decreases when the interval between fractions is increased (81).

Twenty-four hours after whole-body gamma radiation, the basal short circuit current, transepithelial potential and resistance were altered and isotope flux experiments revealed that the increased short circuit current resulted in part from stimulation of active serosal to mucosal net chloride flux (82). After multiple daily fractionation doses of abdominal radiation, disaccharidase and dipeptidase activities increased, decreased and then returned to normal (83).

The morphological effects of abdominal radiation are likely the result of the stem cells in the crypt reacting to irradiation in two ways; first, by shortening the cell cycle in cycling cells and secondly, by an entry into the cell cycle by other dormant cells (84). The crypt contains some extremely sensitive cells and possesses a remarkable ability to repair and repopulate any cells lost as a consequence of cytotoxic insult. The crypt contains many clonogenic epithelial cells. The paradox between the extreme sensitivity of some cells, the more conventional sensitivity of the clonogenic cells, and the resistance or tolerance of the tissue as a whole implies efficient tissue homeostatic mechanisms.
Cytotoxic therapy also impairs crypt cell kinetics, but as well may have a direct effect on small intestinal transport of water, sodium and glucose (85). Ultrastructural changes may be confined to the immature crypt cell population (86). Some $48 \mathrm{~h}$ following intravenous administration of mitomycin $\mathrm{C}$ to rats, there was decreased active glucose uptake in to the brush border membrane vesicles with increased diffusional permeability to glucose (87).

Radiation therapy may affect tissue through long term transformation such as point mutation, but most of the radiation effect results in immediate molecular damage, possibly due to free radicals produced from intracellular water interacting with DNA to prevent replication, transcription and protein synthesis (88). Radiation enteritis is a progressive disease and perforation or fistula formation indicates a poorer prognosis than does stricture or hemorrhage (89). In addition to these morphological and clinical complications, ionizing radiation has pronounced effects on both the physiology and biochemistry of the gastrointestinal tract (90-95).

The contents within the intestinal lumen at the time of exposure to radiation may influence the subsequent development of injury; both bile and pancreatic secretions enhance acute radiationinduced small bowel injury in guinea pigs (96). Bile acid feeding stimulates epithelial cell proliferation and accelerates migration of cells up the villus. Because radiation effects are expressed only during mitosis, the duration of the cell cycle might influence both the number of viable crypts remaining after radiation and the histological parameters. Lack of bile in the intestinal lumen may decrease the rate of cell turnover and thereby render the mucosa less sensitive to the effects of radiation.

Identification of early radiation damage to the intestine would be of value to radiotherapists who might wish to alter the size, portal or rate of dosing. A Schilling test is relatively insensitive as a measure of ileal function, while the ${ }^{14} \mathrm{C}$ glycocholic breath test is associated with a high incidence of both false negative and false positive results.

${ }^{14} \mathrm{C}$-cholylglycine breath tests have 
been used to evaluate ileal function in patients following completion of radiotherapy for pelvic malignancies. Alteration in stool habit and interruption of the enterohepatic circulation caused by radiation develops in nearly all patients who receive pelvic radiotherapy. However, when the glycine conjugates of cholic acid were measured in serum by radioimmunoassay in patients who had undergone pelvic irradiation for gynecologic neoplasms two to seven years previously, there were no differences in postprandial increases between irradiated patients and controls (97). Thus, bile acid malabsorption due to ileal dysfunction is not an inevitable late complication of pelvic radiation, and is not necessarily the major determinant in the pathophysiology of chronic radiationinduced diarrhea. ${ }^{75} \mathrm{SeHCAT}$ is a synthetic conjugated bile acid labelled with the gamma-ray emitting isotope, selenium-75. This isotope can be readily measured by whole body counting techniques, and the test has been shown to be useful for the identification of bile salt malabsorption in patients presenting with diarrhea following pelvic irradiation for treatment of carcinoma of the cervix (98). Prospective studies remain to prove the usefulness of serial measurements of ${ }^{75} \mathrm{SeHCAT}$.

\section{MANAGEMENT}

The management of radiation damage to the small intestine has been reviewed (88). In some patients the development of diarrhea may be ascribed to ileal malabsorption of bile acids, bacterial contamination of the small intestine or to lactose intolerance (99). Studies in rats exposed to 5 to 12 Gy radiation raised the possibility that plasma $\mathrm{DAO}$ activity might be useful as a biological marker of intestinal epithelial injury and recovery after acute radiation exposure (100). Enteral support using nasoduodenal infusion of defined formula liquid diets may be useful to decrease fecal fluid and energy losses in patients suffering from radiation enteritis. Terminal ileal resection followed by an ileal transverse anastomosis and rectosigmoid resection, anastomic leak and death has been less frequent (101).

A number of sulphydryl-containing compounds have been developed, including WR 2721, which appears to be superior to cysteamine in protecting mice against whole body radiation. WR 2721, when given intraperitoneally, may protect the jejunum of animals from radiation damage, and a radioprotective effect is noted when intracolonic WR 2721 is given to mice (102).

\section{REFERENCES}

1. Bertaccini G, Coruzzi G. Receptors in the gastrointestinal tract. Pharm Res Comm 1987:19:87-118.

2. Morita A, Miura S, Erickson RH. Sleisenger MH, Kim YS. Comparison of brush border membrane glycoproteins and glycoenzymes in the proximal and distal rat small intestine. Biochim Biophys Acta 1986;883:506-15.

3. Dudija PK, Brasitus TA. Identification and partial characterization of phospholipid methylation in rat small-intestinal brush-border membranes. Biochim Biophys Acta 1987:919:307-10.

4. Ohyashiki T, Ohtsuka T, Mohri T. A change in the lipid fluidity of the porcine intestinal brush border membranes by lipid peroxidation. Studies using pyrene and fluorescent stearic acid derivatives. Biochim Biophys Acta 1986;861:311-8.

5. Field FJ, Albright EJ, Nathur SN. Effect of dietary $\mathrm{n}-3$ fatty acids on HMG-CoA reductase and ACAT activities in liver and intestine of the rabbit. J Lipid Res 1987;28:50-8.

6. Song I-S, Yoshioka M, Erickson RH. Miura S, Guan D, Kim YS.

Identification and characterization of brush border membrane bound neutral metalloendopeptidases from rat small intestine, Gastroenterology 1986;91:1234-42.

7. Hua JC, Berger J, Pan, Y-CE, Hulmes JD, Udenfriend S. Partial sequencing of human adult, human fetal, and

bovine intestinal alkaline phosphatases: Comparison with the human placental and liver isozymes. Proc Natl Acad Sci USA 1986;83:2368-72

8. Semenza G. Anchoring and biosynthesis of stalked brush border membrane proteins: Glycosidases and peptidases of enterocytes and renal tubuli. Ann Rev Cell Biol $1986: 2: 255-313$.

9. Lorenzsonn V, Korsmo H, Olsen WA. Localization of sucrase-isomaltase in the rat enterocyte. Gastroenterology 1987:92:98-105

10. Reisenauer AM, Gray GM. Abrupt induction of a membrane digestive enzyme by its intraintestinal substrate. Science 1984;227:70-2

11. Quaroni A. Crypt cell development in newborn rat small intestine. J Cell Biol 1985:100:1601-10

12. Quaroni A. Development of fetal rat intestine in organ and monolayer culture. J Cell Biol 1985; 100:1611-22.

13. Wolf JL, Dambrauskas R, Sharpe AH, Trier JS. Adherence to and penetration of the intestinal epithelium by reovirus type 1 in neonatal mice.

Gastroenterology 1987:92:82-91.

14. McClugage SG, Low FN, Zimny ML. Porosity of the basement membrane overlying Peyer's patches in rats and monkeys. Gastroenterology 1986;91:1128-33

15. Winne D, Gorig H, Muller U. Closed rat jejunal segment in situ: Role of pre-epithelial diffusion resistance (unstirred layer) in the absorption process and model analysis. Naunyn-Schmiedeberg's Arch Pharmacol 1987;335:204-15.

16. Holtzheimer G, Winne D. Influence of dietary fiber and intraluminal pressure on absorption and pre-epithelial diffusion resistance (unstirred layer) in rat jejunum in situ. Naunyn-

Schmiedebergs' Arch Pharmacol 1986;334:514-24

17. Cerda JJ, Robbins FL, Burgin CW, Gerencser GA. Unstirred water layers in rabbit intestine: Effects of guar gum. J Parent Ent Nutr 1987;11:63-6.

18. Karasov WH, Diamond JM. Adaptation of intestinal nutrient transport. In: LR Johnson, ed. Physiology of the Gastrointestinal Tract, 2nd edn. New York: Raven Press,1987:1489-97.

19. Diamond JM, Karasov WH. Adaptive regulation of intestinal nutrient transporters. Proc Natl Acad Sci USA 1987;84:2242-5.

20. Levine GM. Nonspecific adaptation of jejunal amino acid uptake in the rat. Gastroenterology 1986;91:49-55.

21. Thomson ABR, Mclntyre Y, MacLeod]. Keelan M. Adaptation of colonic uptake of hexoses and lipids following ileal resection: Effect of variations in the fat content of the diet. Digestion 1986;35:89-94.

22. Diaz-Juarez JL, Boedga G, Arilla E, Prieto JC. Interaction of vasoactive intestinal peptide with rat small intestinal epithelial cells after intestinal resection. Biosci Rep 1985;5:559-66. 
23. Walker JP, Fujimura M, Sakamoto T, Greeley GH. Townsend CM. Thompson JC. Importance of the ileum in neurotensin released by fat. Surgery 1986;98:224-9

24. Bolufer J, Murillo F, Delgado MJ, Murillo ML. Kinetics of phenylalanine absorption by the rat intestine in vivo after distal resection. Biochim Biophys Acta 1985;820:11-8

25. Thomson ABR. Resection of rabbit ileum: Effect on jejunal structure and carrier-mediated and passive uptake. QJ Exp Physiol 1986;71:29-46.

26. Thomson ABR. Early nutrition and intestinal transport function: Effect of low cholesterol diet. 1 Lab Clin Med 1986; 107:365-77.

27. Loeschke K. Fabritius H. Welter HF Adaptation of electrolyte transport in rat large intestine after proximal resection. Pflugers Arch 1986:406:323-7.

28. Fabritius J, Nell G, Loeschke K Adaptation of electrolyte transport in rat large intestine after proximal resection. II. Colon after $50 \%$ jejunoilectomy combined with cecectomy. Pflugers Arch 1986; 406:328-32

29. Koivisto P. Miettinen TA. Adaptation of cholesterol and bile acid metabolism and vitamin $B_{12}$ absorption in the long-term follow-up after partial ileal bypass. Gastroenterology 1986:90: 984-90.

30. Vanderhoof JA, Euler AR, Park JHY, Grandjean CJ. Augmentation of mucosal adaptation following massive small-bowel resection by 16.16-dimethylprostaglandin $E_{2}$ in the rat. Digestion 1987:36:213-9.

31. Uribe A. Johansson C, Rubio C. Cell proliferation of the rat gastrointestinal mucosa after treatment with $E_{2}$ prostaglandins and indomethacin. Digestion 1987:36:238-45.

32. Wilson HD. Schedl HP. Resection of rat small intestine: Calcium. phosphorus, and fat balances and 1,25-dihydroxycholecalciferol. Am Clin Nutr 1987:45:437-42

33. Wittmann T, Crenner F, Grenier JF Cyclic motor activity and trophicity after jejunal resection and bypass in rats. Dig Dis Sci 1986;31:65-72.

34. Biller JA, Montgomery RK, Grand R] Klagsbrun M, Rosenthal A. Use of a 3T3 cell growth factor assay for the delineation and characterization of humoral trophic factors involved in intestinal adaptation in the rat. Gastroenterology 1986;91:448-55.

35. Corps AN, Brown KD. Stimulation of intestinal epithelial cell proliferation in culture by growth factors in human and ruminant mammary secretions. J Endocrinol 1987; 113:285-90.

36. Fitzpatrick LR, Wang P, Johnson LR
Effect of epidermal growth factor on polyamine-synthesizing enzymes in rat enterocytes. Am I Physiol 1987:252:G209-14

37. Grey VL, Morin CL. Evidence for a growth-stimulating fraction in the rat proximal intestine after small bowel resection. Gastroenterology 1985:89:1305-12

38. Goodlad RA, Wilson TJG, Lenton W. Gregory H, McCullagh KG, Wright NA. Urogastrone-epidermal growth factor is trophic to the intestinal epithelium of parenterally fed rats Experientia 1985:41:1161-3.

39. Goodlad RA, Wilson TJG, Lenton W Gregory H, McCullagh KG, Wright NA. Intravenous but not intragastric urogastrone-EGF is trophic to the intestine of parenterally fed rats. Gut 1987:28:573-82

40. Sigalet D. Thomson ABR Consequences of small bowel resection. Med N Am 1988; 18:3423-32

41. Andersson H, Bosae I, Brummer R-I. et al. Nutritional and metabolic consequence of extensive bowel resection. Dig Dis 1986:4:193-202.

42. Woolf GM, Miller C. Kurlan R. Jeejeebhoy KN. Nutrient absorption in short bowel syndrome. Dig Dis Sci 1987:32:8-15.

43. Gouttebel MC, Saint-Aubert B. Astre C. Joyeux $\mathrm{H}$. Total parenteral nutrition needs in different types of short bowel syndrome. Dig Dis Sci 1986;31:718-23.

44. Ameen VZ, Powell GK, Jones LA. Quantitation of fecal carbohydrate excretion in patients with short bowel syndrome. Gastroenterology 1987:92:493-500

45. Bosaeus I, Carlsson N-G. Andersson H. Low-fat versus medium-fat enteral diets. Scand J Gastroenterol 1986;21:891-6.

46. McIntyre PB. Fitchew M, LennardJones JE. Patients with a high jejunostomy do not need a special diet. Gastroenterology 1986:91:25-33.

47. Jacobsen O, Ladefoged K, Stage JG, Jarnum S. Effects of cimetidine on jejunostomy effluents in patients with severe short-bowel syndrome. Scand Gastroenterol 1986;21:824-8.

48. Stanko RT, Nathan G, Mendelow $H$, Adibi SA. Development of hepatic cholestasis and fibrosis in patients with massive loss of intestine supported by prolonged parenteral nutrition. Gastroenterology 1987:92:197-202

49. Russell CA. Role of dietitians in enteral feeding. Gut 1986;27(S1):58-60

50. Deleeuw IH, Vandewoude MF. Bacterial contamination on enteral diets. Gut 1986;27:56-7.

51. Zarling EJ, Parmar JR, Mobarhan S, Clapper M. Effect of enteral formula infusion rate, osmolality, and chemical composition upon clinical tolerance and carbohydrate absorption in normal subjects. J Parent Ent Nutr $1986: 10: 588-90$

52. Thompson JS. Strategies for preserving intestinal length in the short-bowel syndrome. Dis Colon Rectum 1987;30:208-13

53. Tabata K. Johnson LR. Mechanism of induction of mucosal ornithine decarboxylase by food. Am I Physiol 1986;251:G370-4

54. Seidel ER. Hormonal regulation of postprandial induction of gastrointestinal ornithine decarboxylase activity. Am J Physiol 1986;251:G460-6.

55. Tabata K. Johnson LR. Ornithine decarboxylase and mucosal growth in response to feeding. Am I Physiol 1986;251:G270-4

56. Dowling $\mathrm{RH}$, Hosomi H, Stace $\mathrm{NH}$ et al. Hormones and polyamines in intestinal and pancreatic adaptation. Scand J Gastroenterol 1985:20:84-95.

57. Fitzpatrick LR. Wang P. Eikenburg BE, Haddox MK, Johnson LR. Effect of refeeding on polyamine biosynthesis in isolated enterocytes. Am J Physiol 1986;250:G709-13.

58. Thompson JS, Vaughan WP, Forst CF, Jacobs DL, Weekly JS, Rikkers LF. The effect of the route of nutrient delivery on gut structure and diamine oxidase levels. J Parent Ent Nutr 1987;11:28-32

59. Creutzfeldt W. Folsch UR, Elsenhans B, Ballmann M, Conlon JM.

Adaptation of the small intestine to induced maldigestion in rats Experimental pancreatic atrophy and acarbose feeding. Scand J Gastroenterol 1985:20:45-53

60. Vanderhoof JA, Grandjean C], Kaufman SS, Burkley KT, Antonson DL. Effect of high percentage medium-chain triglyceride diet on mucosal adaptation following massive bowel resection in rats. J Parent Ent Nutr 1984:8:685-9

61. Dowling RH, Miazza BM. Potentiel d'adaptation du tractus gastrointestinal. Existence d'un axe trophique entero-pancreatique, role des hormones et polyamines. Schweiz Med Wschr 1985; 115:963-70.

62. Al-Jurf AS, Younoszai MK. Chapman-Furr F. Effect of nutritional method on adaptation of the intestinal remnant after massive bowel resection. J Pediatr Gastroenterol Nutr 1985;4:245-52.

63. Ford WDA, deVries JE, Ross JS, Malt RA. Effect of luminal contents on postresectional longitudinal and mucosal growth in the ileum of suckling rats. Surgery 1985;98:935-41

64. Debnam ES. Adaptation of hexose uptake by the rat jejunum induced by the perfusion of sugars into the distal ileum. Digestion 1985:31:25-30. 
65. Levine GM. Nonspecific adaptation of jejunal amino acid uptake in the rat. Gastroenterology 1986:91:49-55.

66. Weser E, Babbitt J, Hoban M, Vandeventer A. Intestinal adaptation: Different growth responses to disaccharides compared with monosaccharides in rat small bowel. Gastroenterology 1986;91:1521-7.

67. Johnson IT, Gee JM. Gastrointestinal adaptation in response to soluble non-available polysaccharides in the rat. Br J Nutr 1986;55:497-505.

68. Rebolledo E, Andres D, Gonzalez A, Taboada C, Lamas A, FernandezOtero P. Effects of fish meal as source of protein on intestinal maltase activity and intestinal and renal leucine aminopeptidase activity of growing rats. Ann Nutr Metab 1986;30:365-8.

69. Zarling EJ, Mobarhan S. Effect of restricting a balanced diet on rat intestinal disaccharidase activity and intestinal architecture. J Lab Clin Med 1987; 109:556-9.

70. Holt PR, Wu S, Yeh K-Y. Ileal hyperplastic response to starvation in the rat. Am J Physiol 1986:251:G124-31.

71. Wilson HD, Miller T, Ogesen B, Schedl HP. Failla ML, Loven DP. Adaptation of the duodenum and ileum of the rat to mid-gut resection: Enzyme activity and trace metal status. Am J Clin Nutr 1986:43: 185-93.

72. Targan SR, Kagnoff MF, Brogan MD, Shanahan F. Immunologic mechanisms in intestinal diseases. Ann Intern Med 1987; 106:853-70.

73. Rosemurgy AS, Schraut WH. Small bowel allografts. Sequence of histologic changes in acute and chronic rejection. Am J Surg 1986;151:470-5.

74. Lee KKW, Schraut WH. Structure and function of or thotopic small bowel allografts in rats treated with cyclosporine. Am J Surg 1986;151:55-60.

75. Schraut WH, Abraham VS, Lee KKW. Portal versus caval venous drainage of small bowel allografts: Technical and metabolic consequences. Surgery 1986:193-8.

76. Deltz E, Ulrichs K, Schack T, et al. Graft-versus-host reaction in small bowel transplantation and possibilities for its circumvention. Am J Surg 1986;151:379-86.

77. Harmel RP Jr, Stanley M. Improved survival after allogeneic small intestinal transplantation in the rat using cyclosporine immunosuppression.
J Pediatr Surg 1986;21:214-7.

78. Smith DH, Decosse JJ. Radiation damage to the small intestine. World J Surg 1986;10:189-94.

79. Dewit L, Oussoren Y. Late effects in the mouse small intestine after a clinically relevant multifractionated radiation treatment. Radiat Res 1987; 110:372-84

80. Chwalinski S, Potten CS. Influence of irradiation or thymidine ( $T d R$ ) on the pattern of ${ }^{3} \mathrm{H}-\mathrm{TdR}$ incorporation at each cell position in the crypts of the small intestine of the mouse. Int J Radiat Biol 1987;51:243-54.

81. Jensen MH, Sauer T, Reitan JB, Nygaard K. Late radiation enteropathy following split-dose irradiation of rat small intestine. Acta Radiol (Oncology) 1986;25:203-6.

82. Gunter-Smith PJ. Gamma radiation affects active electrolyte transport by rabbit ileum: Basal $\mathrm{Na}$ and $\mathrm{Cl}$ transport. Am J Physiol 1986; 250:G540-5.

83. Becciolini A, Giache V, Balzi M, Morrone A. Brush border intestinal enzymes after multiple daily fractionation. Radiat Res 1987; 109:374-81.

84. Tsubouchi S, Potten CS. Recruitment of cells in the small intestine into rapid cell cycle by small doses of external q or internal b-radiation. Int J Radiat Biol 1985; $48: 361-9$.

85. Pinkerton CR, Booth IW, Milla P] Topical methotrexate alters solute and water transport in the rat jejunum in vivo and rabbit ileum in vitro. Gut 1985;26:704-9.

86. Cunningham D, Morgan RJ, Mills PR, et al. Functional and structural changes of the human proximal small intestine after cytotoxic therapy. J Clin Pathol 1985;38:265-70.

87. Mizuno M, Hamaura T, Hashida M. Sezaki H. Changes in D-glucose uptake by brush border vesicles from small intestine of rats treated with mitomycin C. Biochem Pharmacol 1986;35:1153-8.

88. Smith DH, Decosse JJ. Radiation damage to the small intestine. World J Surg 1986;10:189-94.

89. Galland RB, Spencer J. The natural history of clinically established radiation enteritis. Lancet 1985; ;:1257-8.

90. Thomson ABR, Cheeseman CI, Walker K. Effect of abdominal irradiation on kinetic parameters of intestinal uptake of glucose, galactose, leucine and gly-leucine in the rat. J Lab Clin Med 1983;102:813-27.

91. Thomson ABR, Cheeseman CI, Walker K. Intestinal uptake of bile acids: Effect of external abdominal irradiation. Int J Radiat Oncol Biol Phys $1984 \mathrm{a} ; 10: 671-85$.

92. Thomson ABR, Cheeseman CI, Walker K. Effect of external abdominal irradiation on the dimensions and characteristics of barriers to passive transport in the rat intestine. Lipids 1984b;19:405-18.

93. Thomson ABR, Keelan M, Cheeseman CI, Walker K. Fractionated low doses of abdominal irradiation alters jejunal uptake of nutrients. Int ] Radiat Oncol Biol Phys 1986a; 12:917-25.

94. Thomson ABR, Cheeseman CI, Walker K. Late effects of abdominal radiation on intestinal uptake of nutrients. Radiat Res 1986b; 107:344-53.

95. Keelan M, Thomson ABR. Cheeseman CI, Walker K. Effects of external abdominal irradiation on intestinal morphology and brush border membrane enzyme and lipid composition. Radiat Res 1986;105:84-6.

96. Mulholland MW, Levitt SH, Song CW. Potish RA, Delaney JP. The role of luminal contents in radiation enteritis. Cancer 1984:54:2396-404

97. Schuster JJ, Stryker JA, Demers LM, Mortel R. Absence of bile acid malabsorption as a late effect of pelvic irradiation. Int J Radiat Oncol Biol Phys 1986;12:1605-10.

98. Ludgate SM, Merrick MV. The pathogenesis of post-irradiation chronic diarrhea: Measurement of SeHCAT and $B_{12}$ absorption for differential diagnosis determines treatment. Clin Radiol 1985;36:275-8.

99. Beer WH, Fan A, Halsted CH. Clinical and nutritional implications of radiation enteritis. Am J Clin Nutr 1985:41:85-91

100. Ely MJ, Speicher JM, Catravas GN, Snyder SL. Radiation effects on diamine oxidase activities in intestine and plasma of the rat. Radiat Res 1985; 103:158-62.

101. Galland RB, Spencer J. Surgical management of radiation enteritis. Surgery 1986;99:133-9

102. France HG Jr, Jirtle RL, Mansbach CM II. Intracolonic WR 2721 protection of the rat colon from acute radiation injury. Gastroenterology 1986;91: 644-50. 


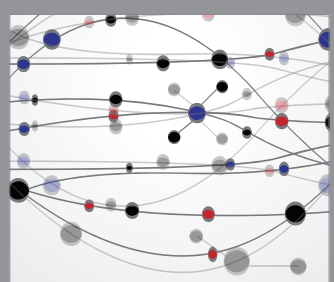

The Scientific World Journal
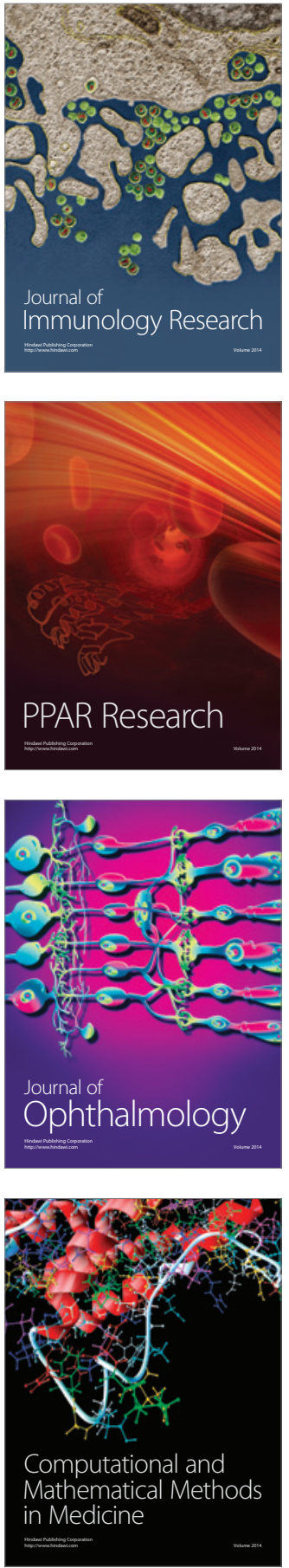

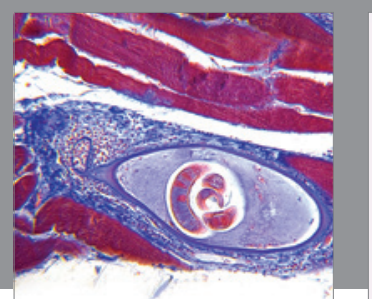

Gastroenterology Research and Practice

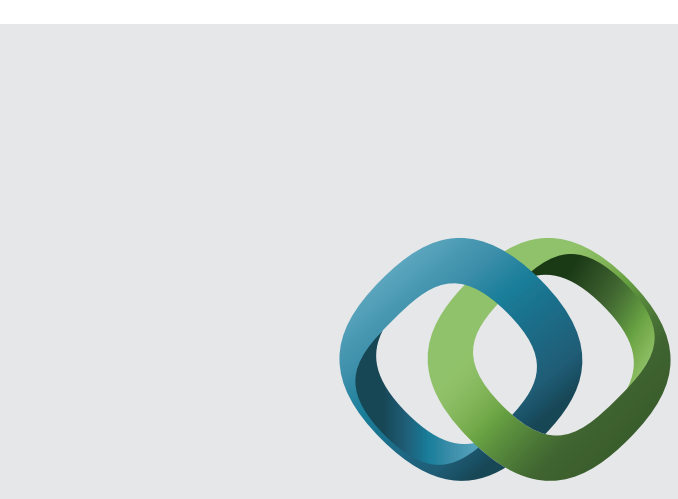

\section{Hindawi}

Submit your manuscripts at

http://www.hindawi.com
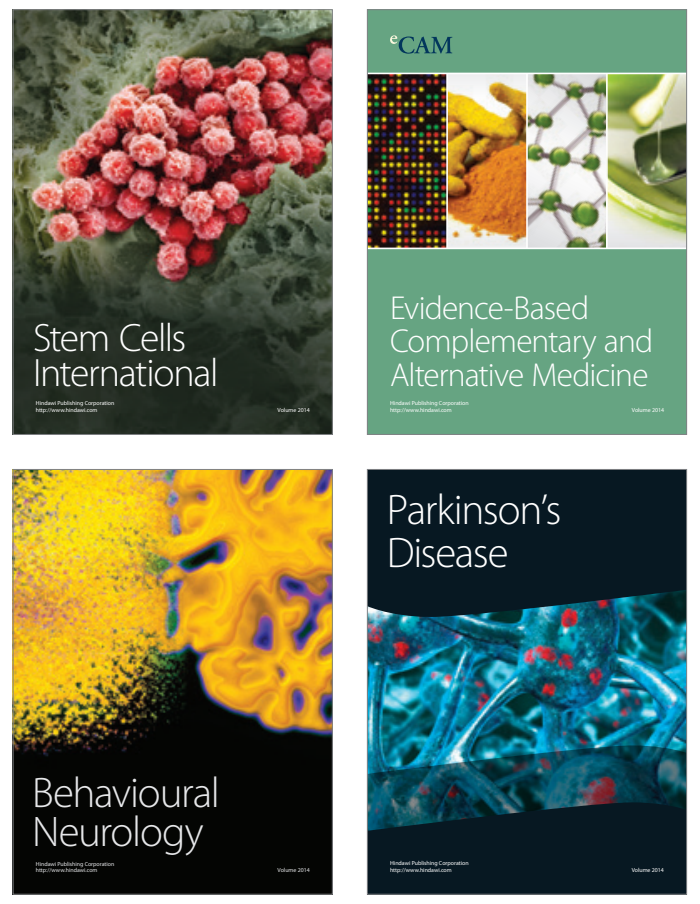
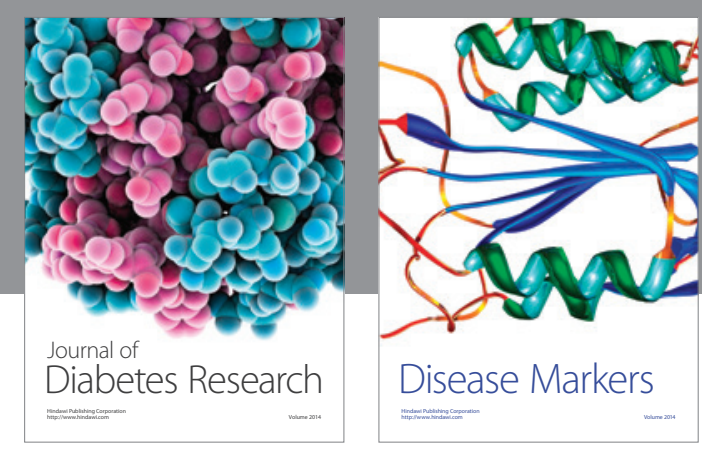

Disease Markers
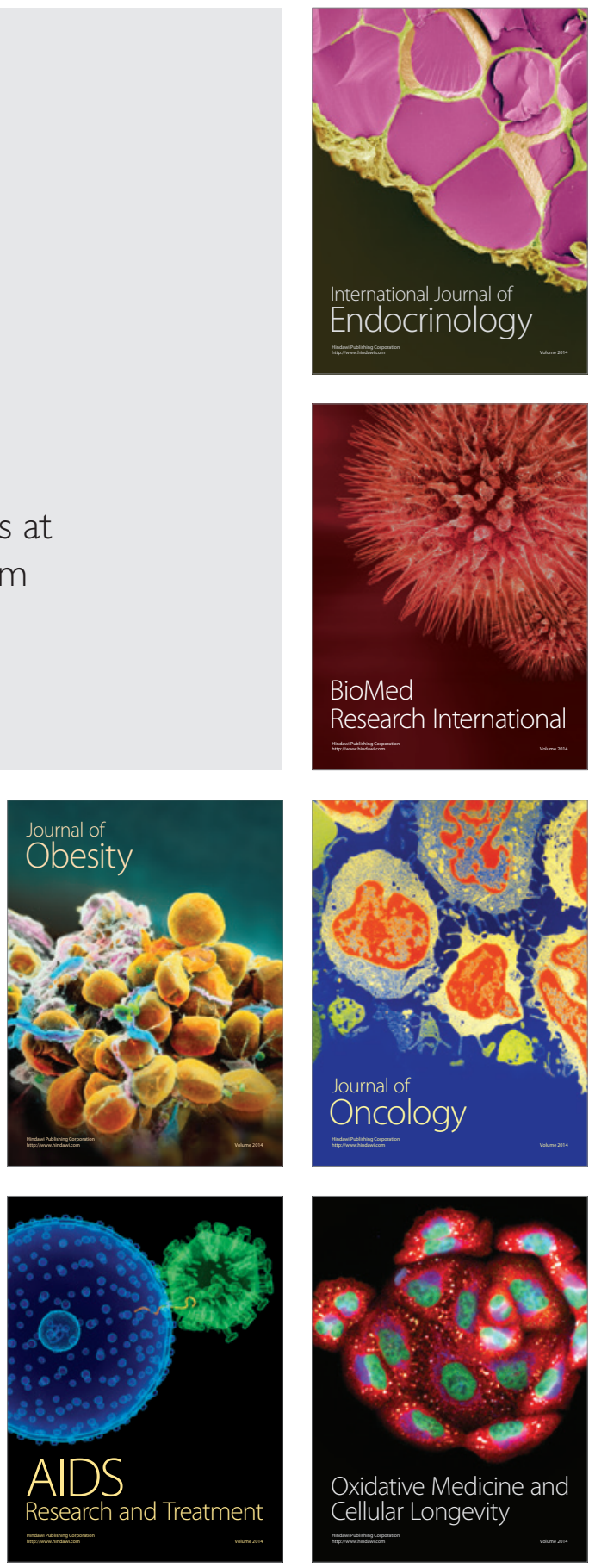